\title{
Die bepaling van die kragverspreiding in die drakabel van 'n sweefspoor
}

\author{
P.J.Vermeulen en J.A.Snyman* \\ Departement Meganiese Ingenieurswese, Universiteit van Pretoria 0002 \\ Ontvang 10 Julie 1992; aanvaar 29 Junie 1993
}

\section{UITTREKSEL}

Die ontleding van kragte in die uniforme drakabel van 'n sweefspoor vir die vervoer van erts tussen 'n myn en 'n veredelingsaanleg word beskryf. Vir die doeleindes van die analise is die probleem as 'n statiese ew'ewigsprobleem beskou. Die elastisiteit van die drakabel, die beweging daarvan ten opsigte van die steunpunte op die dratorings nadat dit met ertskarre gelaai word, die gewig van die gelaaide ertskarre sowel as die trektoukragte word in ag geneem. Aangesien die drakabel baie styf gespan is, is die invloed van buigmomente nalaathaar en kan die kabel as 'n perfekte buigbare kabel beskou word. Die vorm van die drakabel en die trekkrag in die kabel kan deur diskrete modellering bepaal word en in besonder word hier van 'n puntmassamodel gebruik gemaak. Die analise lewer die maksimum krag en die ooreenkomstige posisie van dié krag vir verskillende verteenwoordigende posisies van die gelaaide ertskarre op die drakabel. Dit maak die berekening van veiligheidsfaktore vir verskillende tipes drakabels moontlik.

\section{ABSTRACT \\ The determination of the force distribution in the carrying cable of a cableway}

The analysis of the forces in the uniform carrying cable of a cableway, used for conveying ore to an enrichment plant, is described. For the purpose of the analysis the problem is considered as a static equilibruim problem. The elasticity of the cable, its motion relative to the pylon supports after loading with carts, the weights of the loaded ore carts, and the forces exerted by the towing rope are taken into consideration. Since the cable is pulled taut the influence of bending moments is negligible and consequently the cable may be considered as a perfectly flexible cable that may be modelled by discrete modelling. In particular, use is made of a point mass model. The analysis gives the maximum tensile force and the corresponding position of this force for different representative positions of the loaded carts along the carrying cable. This enables the computation of safety factors for different types of cables.

\section{INLEIDING}

Hierdie artikel beskryf die ontleding van kragte in ' $n$ drakabel vir die vervoer van erts tussen 'n myn en 'n veredelingsaanleg. Vir die voorbeeld onder beskouing is die afstand tussen die myn en die veredelingsaanleg ongeveer $1,5 \mathrm{~km}$ en tien ongelyk gespasieerde pilonne ondersteun die drakabel oor hierdie afstand. n Skematiese voorstelling van 'n gedeelte van die stelsel word in figuur 1 uitgebeeld. Die steunpuntposisies van die drakabel word grafies in figuur 6 aangedui. Vir die doeleindes van die analise word die probleem as 'n statiese ewewigsprobleem hanteer en word die ossillasie van die ertskarre byvoorbeeld nie in berekening gebring nie. Die elastisiteit van die dratou en die beweging daarvan ten opsigte van die steunpunte op die dratorings nadat dit met ertskarre gelaai is, sowel as die invloed van die kragte in die trektou op die kragte in die dratou, word wel in ag geneem. Daar word aanvaar dat die ertskarre op gelyke afstande gespasieer is.
Die belangrikste resultate wat uit die analise vir 'n gegewe kabel verlang word, is die maksimum krag en die ooreenkomstige posisie van dié krag vir verskillende verteenwoordigende posisies van die gelaaide ertskarre op die dratou. Die analise word uitgevoer vir 'n voorgeskrewe en gegewe voorkrag op die onbelaste dratou by steunpunt 1 . Hierdie voorkrag verteenwoordig 'n konfigurasie waar die onbelaste (sonder ertskarre) dratou 1,02 $\mathrm{m}$ onder dratoring 6 vryhang, indien dit daar van die ondersteunde saal afgehaal word. Die eksakte onuitgereikte totale lengte van die drakabel is onbekend. Die volledige ondersoek is vir die Haggie "half locked coil" kabel' en die TrefilARBED "fully locked guide (two shaped wire layers)" kabel ${ }^{2}$ uitgevoer. Verdere besonderhede aangaande die kabels word onder RESULTATE gegee.

Navorsers het reeds getoon dat dit moontlik is om die vorm van 'n statiese, kontinue perfekte buigbare kabel, en 


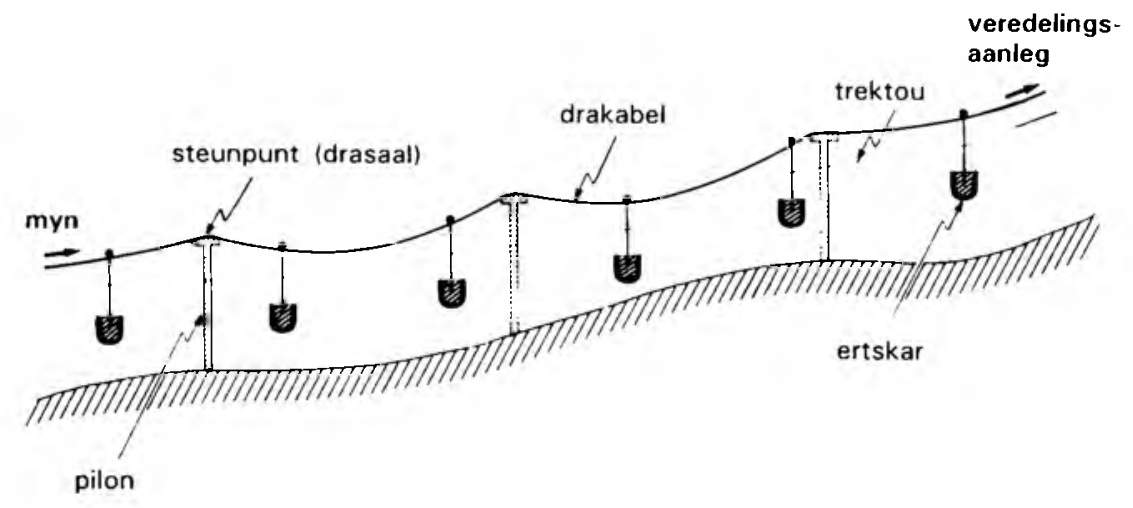

FIGUUR 1: 'n Skematiese voorstelling van 'n gedeelte van die kabelspoorstelsel.

die trekkrag in die kabel, deur diskrete modellerıng te bepaal. Die kabel word gemodelleer deur óf "n eindige aantal puntmassas wat met gewiglose toue verbind is soos beskryf deur Snyman en Vermeulen", of deur 'n aantal starre stafies wat vry by hulle eindpunt kan skarnier volgens die voorbeeld van Dreyer en Murray. ${ }^{4}$ In die geval van die sweefspoorkabel wat hier beskou word, is die kabel baie styf gespan sodat die kromming uiters klein is en die invloed van buigmomente dus as nalaatbaar beskou kan word. Gevolglik is die puntmassabenadering van Snyman en Vermeulen deurgaans in die analise van die drakabel gebruik.

Die wisk undige analise is in drie fases uitgevoer. In die eerste fase is die totale natuurlike (onuitgerekte) lengte van die dratou bepaal wat, vir die gegewe voorkrag $T_{1}^{\prime}$ by dratoring 1 (laaipunt), tot by steunpunt 10 span. In die tweede fase is die invloed van die gelaaide ertskarre in berekening gebring onder die aanname dat 'n krag raaklynig aan die dratou deur die trektou gegee word wat voldoende is om die karre in ewewig te hou. Hierdie analise lewer ' $n$ benaderde vorm van die dratou. In die derde en finale fase is die vorige konfigurasie gebruik om die invloed van die kragte in die trektou meer akkuraat in berekening te bring en is die finale vorm van en kragteverspreiding langs die dratou bereken.

\section{WISKUNDIGE MODELLERING}

\section{Model vir fase 1 (bepaling van die natuurlike lengte van die dratou)}

Beskou die ewewig van 'n element, van natuurlike lengte $\delta$ en massa per eenheidslengte $\mu$, van die kabel soos aangetoon in figuur 2(a). In die geval van 'n styf gespande $\mathrm{kabel}$, is die kromming uiters klein en is die invloed van buigmomente nalaatbaar. Die kragte wat op die j-element inwerk, is dus slegs die twee raaklynige trekkragte van groottes $T_{j}$ en $T_{j+1}$ by die eindpunte en die gewig van die element van massa $\mathrm{m}=\mu \delta$. Die hoeke wat die onderskeie trekkragte met die horisontaal maak, word deur $\theta_{j}$ en $\theta_{j+1}$ onderskeidelik aangedui.

Indien die kromming en lengte van die element $\delta$ relatief klein is (in hierdie studie byvoorbeeld $\delta=1$ meter gekies wat relatief $k$ lein is in vergelyking met die totale lengte van $1500 \mathrm{~m}$ van die kabel), is die ewewig van die kabelelement in figuur 2(a) ekwivalent aan die ewewig van die vereenvoudigde puntmassamodel in figuur $2(\mathrm{~b})$.

Vir ewewig van die puntmodel word vereis dat (a)

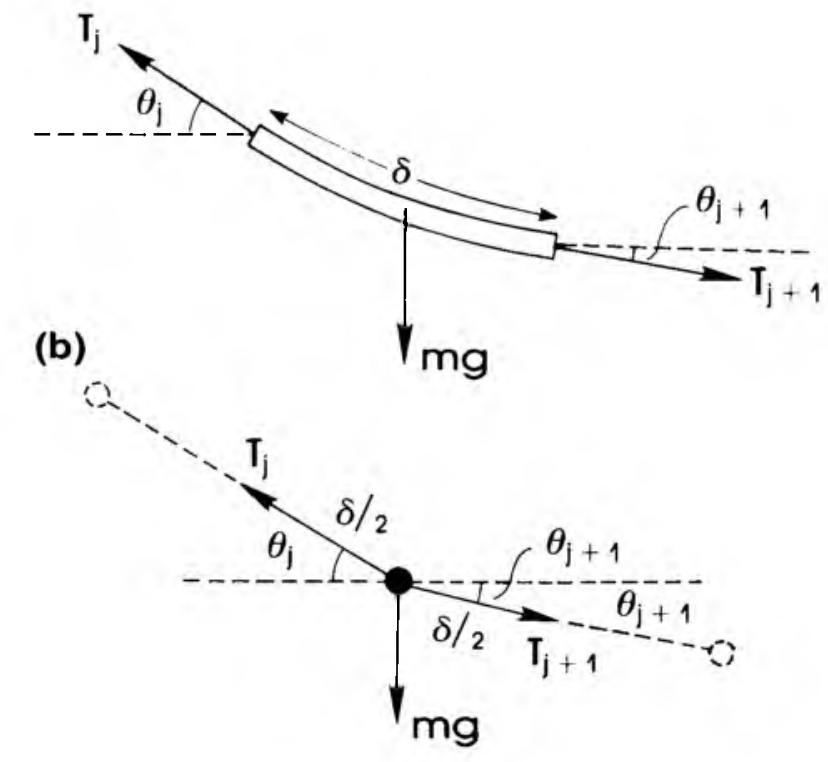

FIGUUR 2: (a) 'n Kontinue kabelelement; (b) 'n ekwivalente puntmassamodel van 'n element.

$$
T_{j} \cos \theta_{j}=T_{j+1} \cos \theta_{j+1}
$$

$$
T_{j} \sin \theta_{j}=m g+T_{j+1} \sin \theta_{j+1}
$$

vir $\mathrm{j}=1,2, \ldots, \mathrm{N}$ waar $\mathrm{N} \delta$ die onuitgerekte lengte van die kabel oor 'n spanwydte is. Vanuit (1) en (2) volg nou dat

en

$$
\theta_{j+1}=\tan ^{-1}\left[\frac{T_{j} \sin \theta_{j}-m g}{T_{j} \cos \theta_{j}}\right]
$$

$$
T_{j+1}=T_{j} \cos \theta_{j} / \cos \theta_{j+1}
$$

Uitdrukkings (3) en (4) kan nou gebruik word om, vir 'n gegewe voorkrag by dratoring 1 , die natuurlike lengte van die totale dratou vanaf dratoring 1 tot by die finale steunpunt 10 te bereken.

As die voorkrag $T_{1}$ vir die eerste spanwydte van dratoring 1 na 2 bekend is, $T_{1}=T_{1}^{0}$ voorgeskryf, dan, op voorwaarde dat die beginhoek $\theta_{1}$ ook bekend is, kan die vorm van die kabel, asook die variasie van die trekkrag langs die kabel, bereken word deur agtereenvolgens (3) en 


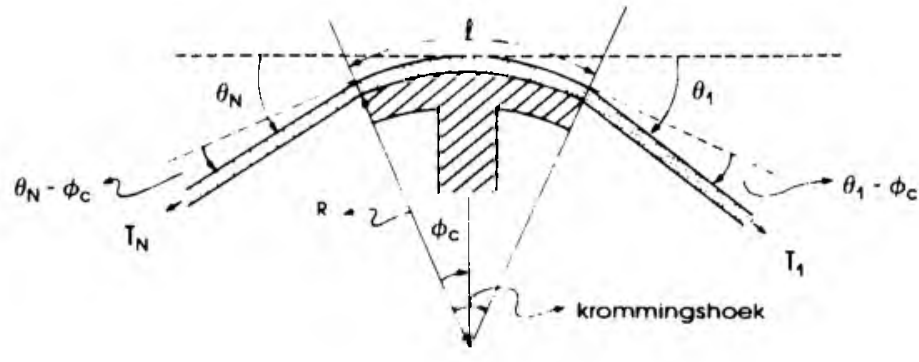

FIGUUR 3: Ondersteuning van die drakabel deur die glad gesmeerde drasaal van 'n pilon.
(4) toe te pas om $\theta_{2}, \theta_{3, \cdots}, \theta_{\mathrm{N}}$ en $\mathrm{T}_{2}, \mathrm{~T}_{3}, \ldots, \mathrm{T}_{\mathrm{N}}$ te bereken. In die praktyk is $\theta_{1}$ egter nie bekend nie. In die oplossingsprosedure word dus begin met 'n skatting van $\theta_{1}$ waarvoor die berkenings van die vorm van die kabellyn deur middel van (3) en (4) uitgevoer word. Deur herhaaldelik berekenings van die vorm oor die eerste spanwydte uit te voer en te interpoleer, word agtereenvolgens meer akkurate waardes vir $\theta_{1}$ verkry, totdat 'n $\theta_{1}$ bepaal is wat sodanig is dat die kabellyn by die steunpunt van dratoring 2 uitkom waar die finale hoek en krag deur onderskeidelik $0_{\mathrm{N}}$ en $\mathrm{T}_{\mathrm{N}}$ aangedui word. In die berekening van die vorm van die kabel word toegelaat vir die elastiese uitrekking van die element $j$ van natuurlike lengte $\delta$ onder die invloed van die kragte $T_{j}$ en $T_{j+1}$ deur die toepassing van Hooke se wet oor die element. Die totale lengte van die kabel vir die eerste spanwydte, asook die uitrekking van die kabel, word terselfdertyd bereken. Gevolglik is die onuitgerekte natuurlike lengte $\ell_{1}$ oor die eerste spanwydte ook bekend.

Vir die volgende spanwydte word vereis dat die afmetings en vorm van ' $n$ drasaal by die pilonne in ag geneem word. Figuur 3 dui die situasie by die drasaal van 'n pilon aan vir ' $n$ gegewe krommingstraal $\mathrm{R}$ en lengte $\iota$ van die drasaal. Aangesien die drasaal in die praktyk glad gesmeer is, word aanvaar dat die wrywingskrag wat deur die saal op die drakabel uitgeoefen kan word, nalaatbaar klein is sodat die kabel vry is om oor die saal te gly.

Knikking in die kabel kan voorkom indien $\phi_{N}$ of $\phi_{1}$, afwaarts gemeet (kyk figuur 3), groter is as $\phi_{\mathrm{c}}$, waar $\phi_{\mathrm{c}}$ $=1 / 2$ krommingshoek. In so 'n geval geld vir ewewig dat

$$
T_{N} \cos \left(\theta_{N}-\phi_{c}\right)=T_{1} \cos \left(\theta_{1}-\phi_{c}\right)
$$

Indien geen knikking voorkom nie, vereenvoudig vergelyking (5) na

$$
T_{N}=T_{1}
$$

Vir die tipiese praktiese geval wat voorkom met ' $\mathrm{n}$ krommingstraal $R=5 \mathrm{~m}$ en 'n drasaallengte $\ell=2 \mathrm{~m}$, wat 'n hoek $\phi_{\mathrm{c}}=11,5^{\circ}$ verteenwoordig, is waargeneem dat geen knikking in die kabel by die pilonne voorkom nie. Vergelyking (5.1) is dus deurgaans geldig.

Vir die tweede spanwydte word die berekeningsprosedure vir die eerste spanwydte vervolgens herhaal. $T_{1}$, die beginspanning by die tweede spanwydte, is nou uit vergelyking (5.1) bekend. $\theta_{1}$ word nou weer eens deur interpolasie bepaal sodat die kabellyn oor die tweede spanwydte by die steunpunt van pilon 3 uitkom. Vir hierdie spanwydte word die natuurlike lengte $\ell_{2}$ ook bereken. Op identiese wyse word die berekenings nou vir spanwydtes 3 tot 9 herhaal sodat die kabellyn uiteindelik by steunpunt 10 uitkom. Die totale natuurlike lengte van die kabel word nou gegee deur

$$
L_{0}=\sum_{i=1}^{9} \ell_{i}
$$

\section{Model vir fase 2 (invloed van gelaaide ertskarre)}

Daar word aanvaar dat die gelaaide ertskarre (elk van totale massa $\mathrm{M}=2050 \mathrm{~kg}$ ) gelykgespasieerd, op afstande van $61 \mathrm{~m}$ langs die dratou, ondersteun word. Verder word, as eerste benadering tot die invloed van die trektou (kyk figuur 1), aanvaar dat die trektou die nodige resultante raaklynige krag $S$ uitoefen om die ertskar in ewewig te hou. Die model vir die ertskar word in figuur 4(a) uitgebeeld. $\mathbf{R}$ is die kontakkrag wat die drakabel op die wiele van die ertskar uitoefen. Aangesien die wiele van die ertskar vryelik rol is R loodreg op die dratou. Vir ewewig van die ertskar geld dus dat

$$
S=M g \sin \theta_{j}
$$

en

$$
R=M g \cos \theta_{j}
$$

Die ertskar oefen nou 'n gelyke en teenoorgestelde reaksiekrag op die dratou uit. Die model vir die dratou by die kontakpunt moet dus die reaksiekrag in ag neem soos in figuur 4(b) uitgebeeld. Vir ewewig van die dratou by die kontakpunt word vereis dat

$$
T_{j} \cos \theta_{j}+M g \cos \theta_{j} \sin \theta_{j}=T_{j+1} \cos \theta_{j+1}
$$

en

$$
T_{j} \sin \theta_{j}=T_{j+1} \sin \theta_{j+1}+m g+M g \cos ^{2} \theta_{j}
$$


(a)

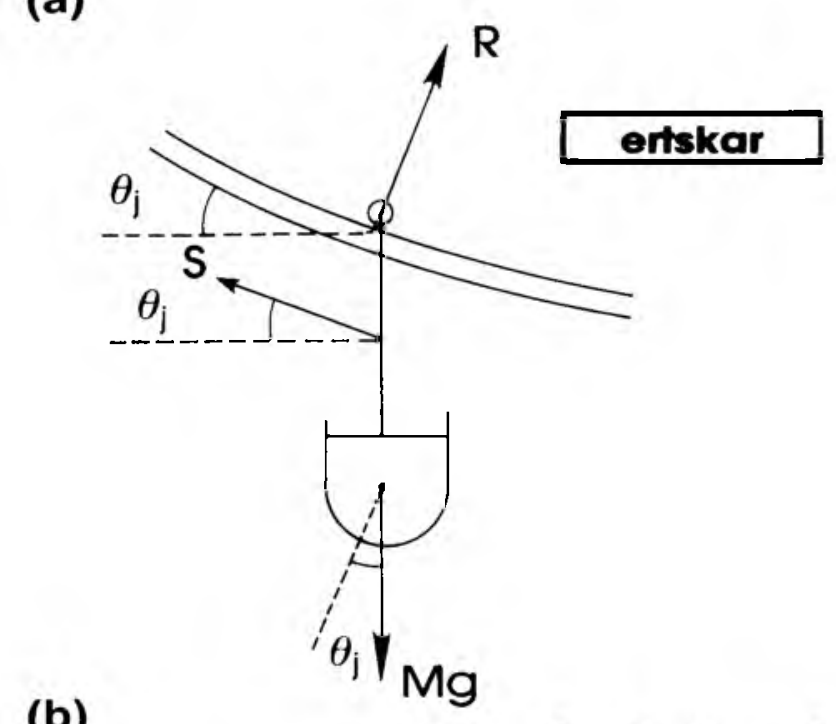

(b)

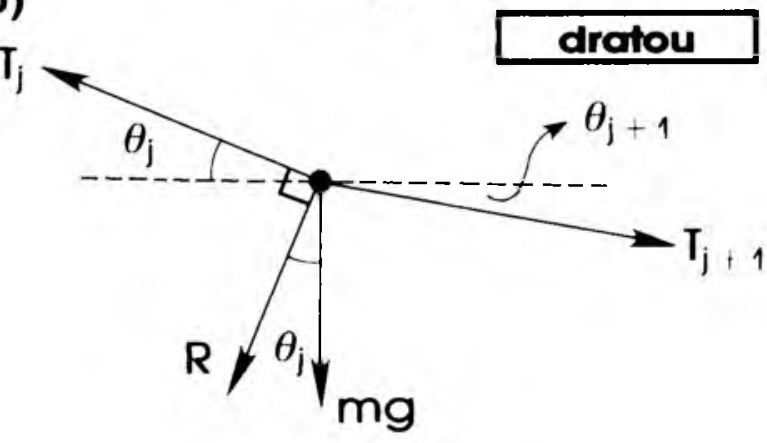

FIGUUR 4: (a) 'n Model van 'n ertskar ondersteun deur die drakabel; (b) 'n dratoumodel by die kontakpunt.

Uit (9) en (10) volg

$\theta_{j+1}=\tan ^{-1}\left[\frac{T_{j} \sin \theta_{j}-m g-M g \cos ^{2} \theta_{j}}{T_{j} \cos \theta_{j}+M g \cos \theta_{j} \sin \theta_{j}}\right]$

en

$$
T_{j+1}=\left(T_{j} \cos \theta_{j}+M g \cos \theta_{j} \sin \theta_{j}\right) / \cos \theta_{j+1}
$$

Vir 'n gegewe $T_{1}$ vir die eerste spanwydte mag die volledige oplossing, dit is die vorms van die dratou en ooreenkomstige trekkragte oor al die spanwydtes, op 'n soortgelyke wyse as in fase 1 bereken word. Hier geld vergelykings (11) en (12) in die plek van (3) en (4) by die ertskarposisies. $T_{1}$ is egter nou onbekend en moet sodanig gekies word dat na berekening van die volledige oplossing die totale natuurlike lengte $\mathrm{L}={ }^{9} \sum_{i=1} \ell_{i}$, wat nou 'n funksie van $T_{1}$ sal wees, ooreen sal stem met die natuurlike lengte $L_{o}$ wat in fase 1 bepaal is. Dit word dus vereis dat

$$
L\left(T_{1}\right)=L_{0}
$$

Die verlangde waarde vir $T_{1}$ word verkry deur die volledige oplossing vir verskillende waardes van $T_{1}$, deur herhaaldelike interpolasies, te bereken totdat (13) eksak bevredig word.

Model vir fase 3 (invloed van die kragte in die trektou)

Met die berekende vorm van die dratou uit fase 2 bekend, kan die meetkunde van die trektou by die ertskarre meer akkuraat in berekening gebring word. In besonder is die hoeke, $\phi_{\text {in }}$ en $\phi_{\text {uit }}$, wat die trektou onderskeidelik vanaf die vorige en na die volgende ertskar met die horisontaal maak, uit fase 2 by benadering bekend. In die analise word die massa van die trektou, wat baie dunner as die drakabel is, buite rekening gelaat en word aanvaar dat die trektoue die ertskarre by benadering reglyning verbind. Dit maak dit moontlik om goeie benaderings tot $\phi_{\text {in }}$ en $\phi_{\text {uit }}$ uit die meetkunde van fase 2 te bereken. Die model wat nou van toepassing is, word in figuur 5 geskets.

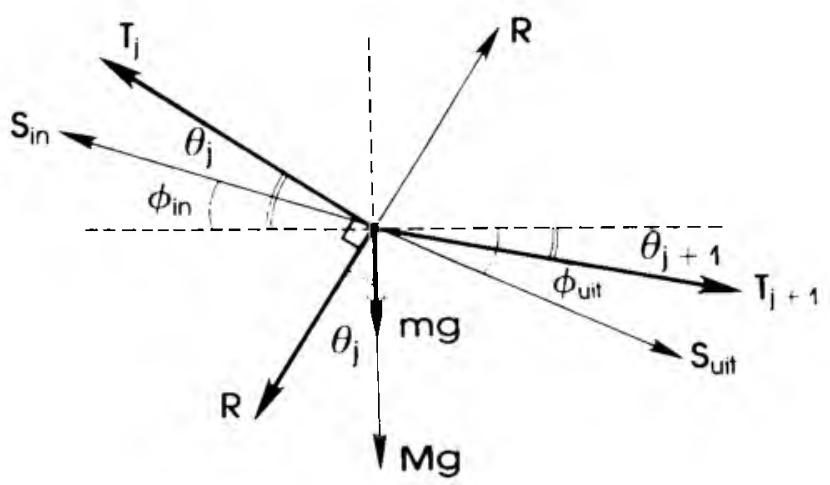

FIGUUR 5: 'n Dratoumodel met inagneming van die kragte in die trektou.

Die vet lyne verwys na die kragte wat op die dratou inwerk, terwyl die dun lyne die kragte op die ertskar voorstel. Hier dui $S_{\text {in }}$ en $S_{\text {uit }}$ onderskeidelik die trekkragte in die trektou vanaf die vorige en na die volgende ertskar aan.

Die ewewig van die ertskar vereis dat

$$
S_{i n} \cos \phi_{i n}=R \sin \theta_{j}+S_{u i t} \cos \phi_{\text {wit }}
$$

en

$$
S_{i n} \sin \phi_{i n}+R \cos \theta_{j}=M g+S_{u i t} \sin \phi_{u i t}
$$

Vanaf (14):

$$
S_{\text {uit }}=\left(S_{\text {in }} \cos \phi_{\text {in }}-R \sin \theta_{j}\right) / \cos \phi_{\text {wit }}
$$

Deur (16) in (15) te stel volg dat

$$
\begin{gathered}
R=\left[S_{i n}\left(\cos \phi_{i n} \tan \phi_{u i t}-\sin \theta_{i n}\right)+M g\right] \\
/\left(\cos \theta_{j}+\sin \theta_{j} \tan \phi_{u i t}\right)
\end{gathered}
$$


Beskou vervolgens die ewewig van die dratou:

$$
\begin{gathered}
T_{j} \cos \theta_{j}+R \sin \theta_{j}=T_{j+1} \cos \theta_{j+1} \\
T_{j} \sin \theta_{j}=R \cos \theta_{j}+m g+T_{j+1} \sin \theta_{j+1}
\end{gathered}
$$

Uit (18) en (19) volg nou dat

$$
\theta_{j+1}=\tan ^{-1}\left[\frac{T_{j} \sin \theta_{j}-R \cos \theta_{j}-m g}{T_{j} \cos \theta_{j}+R \sin \theta_{j}}\right]
$$

en

$$
T_{j+1}=\left(T_{j} \cos \theta_{j}+R \sin \theta_{j}\right) / \cos \theta_{j+1}
$$

Daar word aanvaar dat $S_{\text {in }}$ by elke ertskar reeds bekend is. Vir die eerste ertskar is $S_{\text {in }}$ gelyk aan die gegewe en gewoonlik bekende teenkrag in die trektou $\left(S_{\text {in }}=35 \mathrm{kN}\right.$ vir die geval onder beskouing) by die laaipunt (steunpunt 1). Daarna vir die volgende ertskar sal $S_{\text {in }}$ bekend wees uit die analise vir die vorige $k$ ar. $\left(S_{\text {uit }}\right.$ by vorige ertskar $=S_{\text {in }}$ by volgende ertskar.) Die oplossingsprosedure vir 'n gegewe $T_{1}$ verloop nou soos vantevore behalwe dat by die ertskarre die volgende gewysigde prosedure gevolg word. $\mathrm{R}$ word bereken volgens (17) aangesien $\mathrm{S}_{\text {in }}, \theta_{\mathrm{in}}$ en $\theta_{\text {uit }}$ bekend is. Hierna lewer (16) $S_{\text {uit }}$. Met $R$ bekend volg $\theta_{j+1}$ uit (20) en $T_{j+1}$ uit (21) sodat die berekening van die oplossing langs die dratou voortgesit kan word.

Verder verloop die berekening van die oplossing vir 'n gegewe $T_{1}$ presies soos in fase 2 . Om die finale oplossing te bereken word $T_{1}$ iteratief verstel totdat (13) weer bevredig word. In die praktyk is daar slegs 'n geringe verskil tussen die resultate van fase 2 en 3 en is verdere iteratiewe herhaling van fase 3 oorbodig.

\section{RESULTATE}

'n Stel rekenaarprogramme is ontwikkel om vir enige tipe kabel die berekenings vir fases 1 tot 3 uit te voer. Insette tot die programme is die volgende:

$\mathrm{T}_{1}^{0}=$ voorkrag op onbelaste dratou sodat deursakking by pilon 6 gelyk aan $1,02 \mathrm{~m}$ is

$\mathrm{S}_{\mathrm{in}}^{0} \quad=$ teenkrag in trektou by laaipunt $=35 \mathrm{kN}$

$\delta=$ elementlengte $=1 \mathrm{~m}$

$\mathrm{d} \quad=$ diameter van drakabel in $\mathrm{m}$

$\mu \quad=$ massa per eenheidslengte in $\mathrm{kg} / \mathrm{m}(\mathrm{m}=\mu \delta)$

$\mathrm{r} \quad=$ breukdeel van deursnee-oppervlakte wat metaal is (metaal deursnee-oppervlakte $\left.\mathrm{A}=\mathrm{r} \pi \mathrm{d}^{2} / 4\right)$

$\mathrm{M}=$ massa van gelaaide ertskar $=2050 \mathrm{~kg}$

$\mathrm{E} \quad=$ elastisiteitsmodulus in $\mathrm{GPa}$

$\lambda=$ afstand tussen ertskarre $=61 \mathrm{~m}$

$\mathrm{p}=$ afstand vanaf eerste dratoring na eerste ertskar (berekenings is uitgevoer vir $\mathrm{p}=0 ; 16 ; 31$ en $46 \mathrm{~m}$ )
As verteenwoordigende voorbeelde is die berekenings eerstens uitgevoer vir Haggie $^{1}$ en TrefilARBED ${ }^{2}$ kabels. Die ooreenstemmende data word in tabel 1 gegee.

TABEL 1

Data vir die Haggie en TrefilARBED kabels waarmee die berekenings uitgevoer is

\begin{tabular}{|l|c|c|c|c|c|}
\hline Tipe kabel & $d$ & $\mu$ & $r$ & $E$ & $\mathrm{~T}_{1}^{0}$ \\
\hline & $\mathrm{mm}$ & $\mathrm{kg} / \mathrm{m}$ & & $\mathrm{GPa}$ & $\mathrm{kN}$ \\
\hline $\begin{array}{l}\text { (A) Haggie "1/2 - locked"1 } \\
\text { (B) TrefilARBED "fully locked } \\
\text { (two z-layers)" }\end{array}$ & 44 & 10,805 & 0,815 & 138 & 348 \\
\hline
\end{tabular}

Figuur 6 beeld die algehele variasie van die trekkrag vir onderskeidelik die Haggie en TrefilARBED kabels (beide vir $\mathrm{p}=46$ ) oor al die verskillende spanwydtes uit. Die variasie in maksimum trekkrag vir die verskillende waardes van $p$, wat ooreenstem met verskillende rangskikkings van die ertskarre, is slegs ongeveer $1 \%$ in beide gevalle. Die algehele maksimum $\mathrm{T}_{\text {maks }}$ kom deurgaans voor vir $\mathrm{p}=46$.

Verdere resultate vir Haggie kabels met groter diameter en ooreenkomstige groter voorkragte $\left(T_{1}^{0}\right)$, wat deursakking by dratoring 6 van $1,02 \mathrm{~m}$ gee, word in tabel 2 saamgevat.

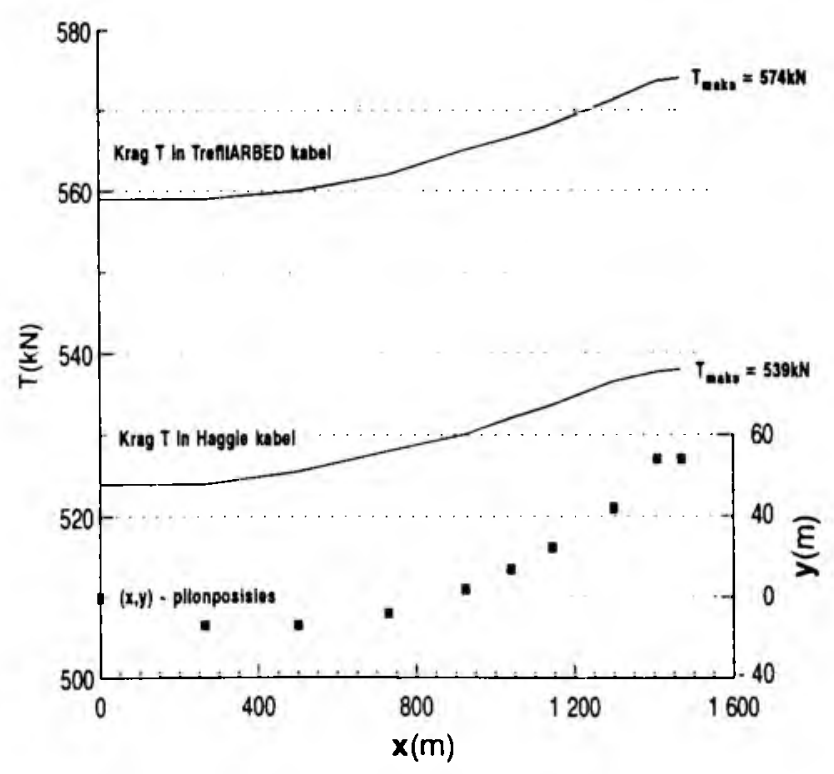

FIGUUR 6: Die $(x, y)$-pilonposisies en die algehele variasie van die trekkrag vir die Haggie en TrefilARBED kabels $(p=46)$ oor die totale spanwydte.

\section{GEVOLGTREKKINGS}

Uit tabel 2 is dit duidelik dat vir die gegewe diameter van $44 \mathrm{~mm}$ die TrefilARBED kabels die grootste veiligheidsfaktor gee, naamlik 2,96 en 3,42 vir die 
TABEL 2

Berekende veiligheidsfaktore vir verskillende Haggie en TrefilARBED kabels

\begin{tabular}{|l|l|l|l|l|l|r|}
\hline $\begin{array}{l}\mathrm{d} \\
\mathrm{mm}\end{array}$ & $\begin{array}{l}\mu \\
\mathrm{kg} / \mathrm{m}\end{array}$ & $\begin{array}{l}\mathrm{T}_{\mathrm{i}}^{0} \\
\mathrm{kN}\end{array}$ & $\begin{array}{l}\text { Tmaks } \\
\mathrm{kN}\end{array}$ & $\begin{array}{l}\text { Treksterkte } \\
\mathrm{MPa}\end{array}$ & $\begin{array}{l}\text { Breekkrag } \\
\mathrm{kN}\end{array}$ & $\begin{array}{l}\text { Veiligheids- } \\
\text { faktor }\end{array}$ \\
\hline 44 (Hag) & 10,805 & 348 & 539,2 & 1350 & 1514 & 2,81 \\
44 (Trefil/ARB) & 11,350 & 366 & 574,0 & 1275 & 1701 & 2,96 \\
44 (Trefil/AR8) & 11,350 & 366 & 574,0 & 1470 & 1963 & 3,42 \\
48 (Hag) & 12,579 & 405 & 598,3 & 1350 & 1759 & 2,94 \\
52 (Hag) & 14,741 & 475 & 668,7 & 1350 & 2064 & 3,09 \\
\hline
\end{tabular}

onderskeie gegewe treksterktes. Om ook 'n veiligheidsfaktor van ongeveer 3,0 te kry, wat gewoonlik as die minimum toelaatbare waarde beskou word, moet 'n Haggie kabel van minstens $48 \mathrm{~mm}$ diameter gebruik word. In die praktyk sal die finale kabelkeuse natuurlik afhang van kostes en die minimum toelaatbare veiligheidsfaktor. 'n Veiligheidsfaktor van tussen 3,0 en 4,5 word gewoonlik, afhangende van die gebruik, as voldoende beskou.

\section{LITERATUURVERWYSINGS}

1. Haggie Katalogus. (1976). Haggie Steel Ropes Ltd., Jupiter, Johannesburg, 2001.

2. TrefilARBED Katalogus. Tecdraft (Edms) Bpk., Posbus 87757, Houghton, 2196, Johannesburg.

3. Snyman, J. A. \& Vermeulen, P. J. (1979). Numerical determination of the configurations of heavy rotating chains, Applied Mathematical Modelling, 3, 232-235.

4. Dreyer, T. P. \& Murray, D. M. (1985). Pre-elimination approach to the modelling of segmented representations of cable shape with application to the positioning of a towed sensor, Applied Mathematical Modelling, 9, 163-169. 